See discussions, stats, and author profiles for this publication at: https://www.researchgate.net/publication/314113414

\title{
Effects of testosterone administration on liver structure and function in aging
} rats

Article in The Aging Male · February 2017

DOI: $10.1080 / 13685538.2017 .1284779$

CITATION

1

7 authors, including:

Ricardo Aparecido Baptista Nucci

University of São Paulo

8 PUBLICATIONS 9 CITATIONS

SEE PROFILE

Walter Krause Neto

Universidade São Judas Tadeu

28 PUBLICATIONS 72 CITATIONS

SEE PROFILE
289

Ana Caroline de Souza Teodoro

Universidade Federal de São Paulo

5 PUBLICATIONS 3 CITATIONS

SEE PROFILE

Wellington de Assis Silva

Universidade São Judas Tadeu

7 PUBLICATIONS 11 CITATIONS

SEE PROFILE

Some of the authors of this publication are also working on these related projects:

Morphology View project

Can training parameters influence morphological adaptation of peripheral nervous system in rodents? View project 


\section{Effects of testosterone administration on liver structure and function in aging rats}

Ricardo Aparecido Baptista Nucci, Ana Caroline de Souza Teodoro, Walter Krause Neto, Wellington de Assis Silva, Romeu Rodrigues de Souza, Carlos Alberto Anaruma \& Eliane Florencio Gama

To cite this article: Ricardo Aparecido Baptista Nucci, Ana Caroline de Souza Teodoro, Walter Krause Neto, Wellington de Assis Silva, Romeu Rodrigues de Souza, Carlos Alberto Anaruma \& Eliane Florencio Gama (2017) Effects of testosterone administration on liver structure and function in aging rats, The Aging Male, 20:2, 134-137, DOI: 10.1080/13685538.2017.1284779

To link to this article: http://dx.doi.org/10.1080/13685538.2017.1284779

Published online: 21 Feb 2017.

Submit your article to this journal $\square$

Џll Article views: 27

Q View related articles ๘

View Crossmark data [⁄ 


\title{
Effects of testosterone administration on liver structure and function in aging rats
}

\author{
Ricardo Aparecido Baptista Nucci ${ }^{1}$ (D), Ana Caroline de Souza Teodoro ${ }^{1}$, Walter Krause Neto ${ }^{2}$, \\ Wellington de Assis Silva ${ }^{2}$, Romeu Rodrigues de Souza ${ }^{1,2}$, Carlos Alberto Anaruma ${ }^{3}$, and Eliane Florencio Gama ${ }^{1,2}$ \\ ${ }^{1}$ Department of Aging Sciences, São Judas Tadeu University, São Paulo, Brazil, ${ }^{2}$ Physical Education Department, São Judas Tadeu University, \\ São Paulo, Brazil, and ${ }^{3}$ Physical Education Department, "Julio de Mesquita Filho" São Paulo State University, São Paulo, Brazil
}

\begin{abstract}
Aging males have a decrease in testosterone levels, by which the testosterone treatment may influence in a negatively fashion the liver.

Aim: This study aimed to analyze the effects of aging with or without testosterone administration on the liver components of animals.

Methods: Wistar rats were divided into three groups: 20 months' group (G20), 24 months' group (G24), group treated with testosterone for 16 weeks (GT). All groups were sacrificed at 24 months except for $\mathrm{G} 20$ that was sacrificed at 20 months.

Results: Aging and testosterone treatment alters the body weight (BW), liver weight (LW) and relative liver weight. Besides, testosterone increased the mitogen capacity of hepatocytes. Nonetheless, we reinforce the negative effects of testosterone on old animals' liver as chronic hepatic congestion and/or cholestasis. In addition, we observed that testosterone plays an important role on hepatic glycogen stores.

Conclusions: Our study showed many implications for the knowledge about the effects of aging with or without testosterone administration on old animals' liver.
\end{abstract}

\section{Introduction}

Aging is a continuous process characterized by a progressive decline of the homeostatic control [1]. It is a dynamic and progressive process in which changes occur, both morphological, functional, biochemical and psychological which determine the progressive loss of the individual's ability to adapt to the environment, leading to greater vulnerability and greater incidence of pathological processes $[2,3]$.

Anatomical changes are the most obvious signs of aging and are manifested in the first place [3]. The WHO classifies the elderly starting at 60 years old with most countries considering 65 years old, the beginning of the old age [4]. As for the animals, Wistar rats become mature at 5 or 6 weeks of age and after that, each month of life is equivalent to 2.5 years of a human life. We considered 20 months as older adult animals and 24 months as aged animals [5].

During aging, besides tissue changes, there are also changes in hormonal levels in males, the decrease in testosterone levels stands out [6]. According to Osterberg et al. [7], 20\% of men aged 60 years suffer from

Address for correspondence: Ricardo Aparecido Baptista Nucci, Department of Aging Sciences, São Judas Tadeu University, 546 Taquari St., São Paulo, Brazil. Tel: +55 11 948921783. Fax: +55 11 27991702. E-mail: r.aparecido.nucci@uol.com.br

\section{Keywords}

Liver, aging, testosterone, hepatic structure, male hormone

\section{History}

Received 17 November 2016

Accepted 17 January 2017

Published online 14 February 2017 hypogonadism, which is also called testosterone deficiency syndrome (TDS) [8]. It is known that reposition of this hormone with caution and monitoring [9] determines the increase in muscle tissue and, consequently, an increase in muscle strength [10], decreasing fat tissue and increasing libido. However, supraphysiologic doses of testosterone have been suggested to improve muscle strength and different metabolic parameters in shorter time [10-12]. On the other hand, these exacerbated doses could injure the liver [9,13,14], as well as, other organs as heart and prostate $[6,9,15]$.

Although many physiological effects have been described in the literature regarding the use of testosterone in the liver $[9,13,14]$, there is still unclear evidences about the effects of this steroid on liver structure during aging.

\section{Materials and methods}

All experimental procedures conformed to the guiding principles of the American Physiology Society and were approved by the Ethical Committee of São Judas Tadeu University under the protocol number 001/2013.

To carry out this study, 18 male Wistar rats were used. The rats (20 months of age) were randomly divided into three groups: 20 months' group (G20, $n=6), 24$ months' group (G24,n=6), group treated with testosterone for 16 weeks, 
totaling 24 months (GT, $n=6$ ). The body weight (BW) was measured at the beginning of each week and the final BW was compared.

The hormone used was PERINON ${ }^{\circledR}$ (testosterone propionate, veterinary use) from Perini Laboratory (São José, Brazil), with $100 \mathrm{ml}$ in vial containing $1 \mathrm{~g}$ of testosterone propionate and peanut oil q.s.p. $100 \mathrm{ml}$. The injected dose was $10 \mathrm{mg} / \mathrm{kg}$ [16] to the weight of the animals from GT group. The dosing was administered two times a week. Injections were given throughout 16 weeks totaling 32 intraperitoneal injections.

After the experiments, the animals were sacrificed by $\mathrm{CO}_{2}$ method and the liver was removed. Then fragments of liver were fixed in $10 \%$ buffered formalin and dehydrated in an increasing series of alcohols. They were cleared in xylene, embedded in paraffin, sectioned in $5 \mu \mathrm{m}$ thick sections and stained with hematoxylin and eosin (HE), picrosirius red and periodic acid of Schiff (PAS) for light microscopy analysis.

The histological sections stained with HE were used to analyze the area and the numerical density of hepatocytes and other liver cells using the Axio Vision software (version 4.9.1). For numerical density, we counted all the cells (hepatocytes or other liver cells, e.g. Kupffer and Stellate cells without discrimination) in each field.

In HE histological sections we analyzed, through stereological methods, the volume density of lobular parenchyma components (capillaries sinusoids, perisinusoidal spaces and biliary ducts) and non-lobular parenchyma components (portal spaces, veins and center-lobular branches of blood vessels). The sections stained with picrosirius red were used to analyze the percentage of type I collagen fibers (indicative of fibrosis). Finally, the sections stained with PAS were used to analyze the percentage of glycogen present in the tissue. For the determination of numerical density of collagen and glycogen, Image J software (National Institute of Health, version $1.45 \mathrm{~s}$ ) was used. It was done by counting the number of structures present in the photographic field of microscopic field. The structure which touched the lines to the right and upwards on the screen were disregarded, while those which that touched the lines on the left and downward were considered [17].

The data were presented as mean and standard deviation, and to detect differences between groups, the analysis of variance (ANOVA) was used, followed by Tukey's post-hoc test with a significance level of 5\%. The data were analyzed with the statistical software SPSS, version 21.0 (IBM SPSS Statistics version 21.0).

\section{Results}

Our results show that testosterone treatment in aged rats can produce different outcomes. Testosterone administration reduced significantly the BW. Liver weight (LW) increased with both aging and testosterone administration. Regarding the relative liver weight, the aging process and the use of testosterone increased the hepatic mass (Table 1).

We observed in Table 2 that testosterone treatment showed significant decrease in hepatocyte area, nonetheless increased number of hepatocytes and the number of other liver cells.
Table 3 shows stereological measures, in which the major finding was a possible cholestasis and/or chronic hepatic congestion, characterized by decreased lobular parenchyma components and consequent increase in non-lobular parenchyma, as well as, an increase of collagen fibers type I in GT, indicating fibrosis. Finally, Table 3 also showed increased liver glycogen in GT.

\section{Discussion}

Our study analyzed the effects of testosterone administration on the liver components of old animals. Observing Table 1, we can see that aging increases BW. However, animals that received testosterone showed a significant decrease of the BW when compared with G24, indicating that testosterone influence in BW. This is consistent with an experimental study [18] demonstrating that testosterone can influence BW. In addition, a meta-analysis of randomized clinical trials in old men [19] reported that the use of testosterone decreases body fat and total cholesterol.

We can see that the absolute weight of the liver suffers a sharp increase with both aging and testosterone administration. In order to have no doubts about these results, we performed the relative liver weight, established by the ratio of

Table 1. BW, LW and relative liver weight times 100 (LW/BW \%) of G20, G24 and GT groups.

\begin{tabular}{llll}
\hline Groups & \multicolumn{1}{c}{ BW $(\mathrm{g})$} & \multicolumn{1}{c}{ LW $(\mathrm{g})$} & $\begin{array}{c}\text { LW/BW } \\
(\%) \times 100\end{array}$ \\
\hline G20 $(n=6)$ & $486.30 \pm 38.90$ & $14.60 \pm 1.60$ & $3.01 \pm 0.12$ \\
G24 $(n=6)$ & $644.10 \pm 129.50^{*}$ & $24.80 \pm 4.80^{*}$ & $3.86 \pm 0.16^{*}$ \\
GT $(n=6)$ & $527.30 \pm 48.60 \dagger$ & $20.70 \pm 3.00^{*}$ & $3.96 \pm 0.75^{*}$ \\
\hline
\end{tabular}

Results are means \pm standard deviation, $n=$ number of animals. $* p<0.05$ vs. G20.

$\dagger p<0.05$ vs. G24.

Table 2. Area of nuclei of hepatocytes $\left(\mathrm{ANH} \mu \mathrm{m}^{2}\right.$ ), number of nuclei of hepatocytes (NNH per field) and number of nuclei of other liver cells (OLC per field) of G20, G24 and GT groups.

\begin{tabular}{lllc}
\hline Groups & ANH $\left(\mu \mathrm{m}^{2}\right)$ & NNH (per field) & $\begin{array}{c}\text { OLC } \\
\text { (per field) }\end{array}$ \\
\hline G20 $(n=6)$ & $42.65 \pm 11.21$ & $18.18 \pm 4.24$ & $4.59 \pm 8.90$ \\
G24 $(n=6)$ & $42.79 \pm 10.23$ & $18.95 \pm 6.69$ & $5.93 \pm 12.84$ \\
GT $(n=6)$ & $37.93 \pm 9.20 * \dagger$ & $22.06 \pm 6.38^{*} \dagger$ & $10.70 \pm 22.03 * \dagger$ \\
\hline
\end{tabular}

Results are means \pm standard deviation, $n=$ number of animals. $* p<0.05$ vs. G20. $\dagger p<0.05$ vs. G24.

Table 3. Volume density of lobular parenchyma components (LPC \%), volume density of non-lobular parenchyma (NLP \%), volume density of collagen fibers type I (COL \%) and volume density of hepatic glycogen (GLY \%) of G20, G24 and GT groups.

\begin{tabular}{lllll}
\hline Groups & \multicolumn{1}{c}{ LPC $(\%)$} & \multicolumn{1}{c}{ NLP $(\%)$} & COL $(\%)$ & \multicolumn{1}{c}{ GLY $(\%)$} \\
\hline G20 $(n=6)$ & $22.41 \pm 4.20$ & $5.70 \pm 4.40$ & $3.25 \pm 5.88$ & $6.51 \pm 0.50$ \\
G24 $(n=6)$ & $15.62 \pm 4.80 *$ & $9.80 \pm 8.00 *$ & $3.80 \pm 5.67$ & $6.41 \pm 0.65$ \\
GT $(n=6)$ & $17.57 \pm 3.90 * \dagger$ & $8.67 \pm 6.50 *$ & $6.10 \pm 6.61 *$ & $7.36 \pm 0.35 * \dagger$ \\
\hline
\end{tabular}

Results are means \pm standard deviation, $n=$ number of animals.

$* p<0.05$ vs. G20.

$\dagger p<0.05$ vs. $\mathrm{G} 24$. 
the total liver weight (absolute weight) divided by the final BW of the animal times 100. Regarding to the relative liver weight, we observed that aging is a factor that influences the liver mass gain. Furthermore, our data demonstrate that testosterone increased the relative liver weight. Lydén et al. [20] and Pignata et al. [21] demonstrated the effectiveness of the steroid nandrolone decanoate in increase liver mass even in cases of cancer. Besides, Vieira et al. [14] had similar effects to those described in our study.

In Table 2, we suggest that aging and testosterone influence on the nuclei of hepatocytes. The present study demonstrated that testosterone decreased the area of the nucleus of hepatocytes, increased their numerical quantity and increased the number of nuclei of other liver cells. Michalopoulos and De Frances [22] also highlighted the role of testosterone as mitogen for hepatocytes. This is consistent with studies demonstrating that the Hepatocyte Growth Factor produced by Kupffer cells is a contributing factor in mitosis when the liver suffers chemical, toxic or surgical aggression $[22,23]$. Although, it is not possible to distinguish Kupffer cells and stellate cells properly with the technique used, the increase in the number of these cells could indicate a reaction to a liver injury, since Kupffer cells are part of the phagocytic system and exhibit hyperplasia in response to a systemic imbalance [24].

Table 3 shows the stereological analysis of the volume density of the components of lobular hepatic parenchyma. We found that both aging and testosterone seem to induce a decrease in the components of the lobular parenchyma. The reason for this sharp decline may be related to a hepatic congestion [25]. To corroborate this observation, hepatic congestion would be accompanied by an increase also in the volume density of non-lobular parenchyma, which was found in our analysis.

In the present study, the hepatic NLP was significantly increased in aged animals and after testosterone administration. This is in accordance with other studies which have suggested that hepatic congestion may be a result from the process of aging and the use of testosterone [25-29]. In addition, the groups that received testosterone treatment had a significant increase of collagen fibers type I which can characterize a result fibrosis of chronic hepatic congestion [28]. Furthermore, Lise et al. [30] showed that cholestasis is related to the use of testosterone. Considering that cholestasis involves the bile ducts, the significant changes in the volume density of lobular parenchyma components found in our study, suggest that testosterone administration has modified the bile ducts and its transport. Nevertheless, a further study is needed to determine the effect of testosterone administration on bile production.

The present study demonstrated a significant increase in the volume density of hepatic glycogen in rats by testosterone administration. This is consistent with the finding that the absence of male sex hormones, induced by castration, increases blood glucose without altering circulating levels of insulin [31]. Therefore, it is believed that testosterone may play an independent role, but like that of insulin in glucose uptake mechanism, thus assisting in increasing the hepatic glycogen reserve.
In conclusion, testosterone administration displayed important effects to the liver of old rats. First, testosterone has increased the mitotic capacity of hepatocytes. Second, the results reinforce the negative effects of testosterone on old animals' liver as chronic hepatic congestion and/or cholestasis. Finally, testosterone plays an important role in aging by increasing hepatic glycogen stores.

\section{Acknowledgements}

The authors wish to thank Dr. Carlos Alberto Anaruma, José Roberto Rodrigues da Silva and Eduardo Custódio, "Julio de Mesquita Filho" São Paulo State University, São Paulo, Brazil, and Magna Soares, Butantan Institute, São Paulo, Brazil, for technical support.

\section{Declaration of interest}

The authors report no declaration of interest.

\section{ORCID}

Ricardo Aparecido Baptista Nucci (D) http://orcid.org/00000001-5649-2145

\section{References}

1. Weinert BT, Timiras PS. Invited review: theories of aging. J Appl Physiol 2003;95:1706-16.

2. Vigorito C, Giallauria F. Effects of exercise on cardiovascular performance in the elderly. Front Physiol 2014;5:51. eCollection 2014.

3. López-Otín C, Blasco MA, Partridge L, et al. The hallmarks of aging. Cell 2013;153:1194-217.

4. World Health Organization. Definition of an older or elderly person; 2013. Available from: http://www.who.int/healthinfo/ survey/ageingdefnolder/en/ [last accessed July 2014].

5. Andreollo NA, Santos EF, Araújo MR, Lopes LR. Rat's age versus Human's age, what is the relationship? (Idade dos ratos versus idade humana: qual é a relação?). Arq Bras Cir Dig 2012;25:49-51.

6. Spitzer M, Huang G, Basaria S, et al. Risks and benefits of testosterone therapy in older men. Nat Rev Endocrinol 2013;9: 414-24.

7. Osterberg EC, Bernie AM, Ramasamy R. Risks of testosterone replacement therapy in men. Indian J Urol 2014;30:2-7.

8. Lunenfeld B, Mskhalaya G, Kalinchenko S, Tishova Y. Recommendations on the diagnosis, treatment and monitoring of late-onset hypogonadism in men - a suggested update. Aging Male 2013;16:143-50.

9. Bagatell CJ, Bremner WJ. Androgens in men-uses and abuses. N Engl J Med 1996;334:707-15.

10. Bhasin S, Storer TW, Berman N, et al. The effects of supraphysiologic doses of testosterone on muscle size and strength in normal men. N Engl J Med 1996;335:1-7.

11. Herbst KL, Amory JK, Brunzell JD, et al. Testosterone administration to men increases hepatic lipase activity and decreases HDL and LDL size in 3 wk. Am J Physiol Endocrinol Metab 2003;284: E1112-18.

12. Tan WS, Low WY, Ng CJ, et al. Efficacy and safety of long-acting intramuscular testosterone undecanoate in aging men: a randomised controlled study. BJU Int 2013;111:1130-40.

13. Lee WM. Drug-induced hepatotoxicity. N Engl J Med 2003;349: 474-85.

14. Vieira RP, Franca RF, Damaceno-Rodrigues NR, et al. Dosedependent hepatic response to subchronic administration of nandrolone decanoate. Med Sci Sports Exerc 2008;40:842.

15. Gonçalves L, de Souza RR, Maifrino LBM, et al. Resistance exercise and testosterone treatment alters the proportion of numerical density of capillaries of the left ventricle of aging Wistar rats. Aging Male 2014;17:243-7. 
16. Fitts JM, Klein RM, Powers CA. Comparison of tamoxifen and testosterone propionate in male rats: differential prevention of orchidectomy effects on sex organs, bone mass, growth, and the growth hormone-IGF-I axis. J Androl 2004;25:523-34.

17. Mandarim-de-Lacerda CA. Stereological tools in biomedical research. An Acad Bras Cienc 2003;75:469-86.

18. Aparicio VA, Sánchez C, Ortega FB, et al. Effects of the dietary amount and source of protein, resistance training and anabolicandrogenic steroids on body weight and lipid profile of rats. Nutr Hosp 2013;28:127-36.

19. Isidori AM, Giannetta E, Greco EA, et al. Effects of testosterone on body composition, bone metabolism and serum lipid profile in middle-aged men: a meta-analysis. Clin Endocrinol 2005;63: 280-93.

20. Lydén E, Cvetkovska E, Westin T, et al. Effects of nandrolone propionate on experimental tumor growth and cancer cachexia. Metab Clin Exp 1995;44:445-51.

21. Pignata S, Daniele B, Gallo C, et al. Endocrine treatment of hepatocellular carcinoma. Any evidence of benefit? Eur J Cancer 1998;34:25-32.

22. Michalopoulos GK, De Frances MC. Liver regeneration. Science 1997;276:60-6.

23. Fausto N, Campbell JS, Riehle KJ. Liver regeneration. Hepatology 2006;43:S45-53.

24. Decker K. Biologically active products of stimulated liver macrophages (Kupffer cells). Eur J Biochem 1990;192:245-61.
25. Tanasov VS, Krause Neto W, Gonçalves L, et al. Use of anabolic steroid altered the liver morphology of rats. Int J Morphol 2014;32: 756-60.

26. Zoli M, Magalotti D, Bianchi G, et al. Total and functional hepatic blood flow decrease in parallel with ageing. Age Ageing 1999;28: 29-33.

27. Le Couteur DG, Fraser R, Kilmer S, et al. The hepatic sinusoid in aging and cirrhosis: effects on hepatic substrate disposition and drug clearance. Clin Pharmacokinet 2005;44: 187-200.

28. Gore RM, Mathieu DG, White EM, et al. Passive hepatic congestion: cross-sectional imaging features. Am J Roentgenol 1994;162:71-5.

29. Bento-Silva MT, Martins MDC, Torres-Leal FL, et al. Effects of administering testosterone undecanoate in rats subjected to physical exercise: effects on the estrous cycle, motor behavior and morphology of the liver and kidney. Braz J Pharm Sci 2010;46: 79-89.

30. Lise MLZ, Da Gama e Silva TS, Ferigolo M, et al. O abuso de esteróides anabólico-androgênicos em atletismo. Rev Assoc Méd Brasil 1999;45:364-70.

31. Ramamani A, Aruldhas MM, Govindarajulu P. Differential response of rat skeletal muscle glycogen metabolism to testosterone and estradiol. Can J Physiol Pharmacol 1999;77: 300-4. 